\title{
THE FAILURE OF INTRACRANIAL PRESSURE-VOLUME CHANGE TO INFLUENCE RENAL FUNCTION ${ }^{1}$
}

\author{
By ROBERT A. FISHMAN 2 \\ WITH THE TECHNICAL ASSISTANCE OF ROMAN J. HALLA \\ (From the Department of Neurophysiology, Army Medical Service Graduate School, \\ Walter Reed Army Medical Center, Washington 12, D. C.)
}

(Submitted for publication April 23, 1953; accepted May 15, 1953)

A variety of lesions of the central nervous system may be associated with disturbances of renal function characterized by either the increased urinary loss of sodium and chloride $(1-3)$ or the retention of salt (3-8). It has also been postulated that changes in the excretion of salt, secondary to alterations in the volume of blood or extracellular fluid, are mediated by a "volume receptor" located in the cranial cavity (9-12). The following experiments were therefore undertaken in order to investigate the influence of alterations in intracranial venous volume and pressure, and cerebrospinal fluid (CSF) volume and pressure on renal function.

\section{METHODS}

Female dogs were anesthetized with sodium pentobarbital (30 mg. per $\mathrm{Kg}$.) except for two experiments in which chloralose $(75 \mathrm{mg}$. per $\mathrm{Kg}$.) was used. Urine was collected through an indwelling catheter. The bladder was washed out with distilled water after each collection and emptied completely by blowing out with air. Glomerular filtration rate was measured by the clearance of exogenous creatinine $\left(\mathrm{C}_{\mathrm{C}_{\mathbf{r}}}\right)$ (13) and renal plasma flow was estimated from the clearance of paraminohippurate $\left(C_{P A B}\right)$ (14). Urine was analyzed for sodium with a flame photometer and for chloride titrimetrically (15). Cisternal, femoral arterial, and jugular venous pressures were measured with Statham strain gauges and recorded on a Brush oscillograph. Pressure in the jugular vein was obtained by passing a polyethylene catheter up to the level of the intracranial jugular bulb.

\section{EXPERIMENTAL PROCEDURE AND RESULTS}

Four groups of experiments were performed. Saline, 0.85 per cent, was administered intravenously at 4 or $5 \mathrm{cc}$. per min. by means of a constant infusion pump. After two hours, urinary

\footnotetext{
1 Presented in part at the Fall Meetings of the American Physiological Society, New Orleans, La., Sept. 3-5, 1952.

2 Present address: Neurological Institute, Presbyterian Hospital, New York 32, N. Y.
}

flows of about $3 \mathrm{cc}$. per min. were established. Three ten minute "Control" periods were then obtained, followed by three ten minute "Experimental" periods, and by three ten minute "Recovery" periods. Urine was discarded for five minutes immediately before and after the thirty minute "Experimental" period.

(1) Control: Seven dogs were studied during nine ten minute clearance periods in order to ascertain the normal variations in urinary flow, clearances of creatinine and $\mathrm{PAH}$, and excretion of sodium and chloride, which might occur during this period of time.

(2) Neck compression: Eight dogs were subjected to acute compression of the neck with a blood pressure cuff at $60 \mathrm{~mm}$. Hg during the thirty minute "Experimental" period. This procedure produced a threefold elevation in pressure in the jugular bulb and a secondary twofold rise in cerebrospinal fluid pressure, without altering arterial pressure.

(3) Neck compression and cerebrospinal fluid drainage: Seven dogs were subjected to acute compression of the neck with a blood pressure cuff at $60 \mathrm{~mm}$. $\mathrm{Hg}$ with simultaneous drainage of about $15 \mathrm{cc}$. to $20 \mathrm{cc}$. of CSF to maintain the CSF pressure at minus $150 \mathrm{~mm}$. water during the thirty minute "Experimental" period. This procedure was designed to produce an increase in both volume and pressure of intracranial veins, while decreasing the volume and pressure of cerebrospinal fluid. The pressure in the jugular bulb was tripled but arterial pressure was unaltered.

(4) Intracisternal injection of saline: Twenty dogs were subjected to an increase in CSF pressure by the introduction of normal saline into the cisterna magna, at the rate of $0.5 \mathrm{cc}$. per min. during the thirty minute "Experimental" period, sufficient to maintain a CSF pressure of $500 \mathrm{~mm}$. 
TABLE I

The mean value for each thirty minute period is stated. The means of the difference between each value for the control and experimental periods, and for the experimental and recovery periods, were tested for significance using Fisher's $t$ test for the significance of the mean of a unique sample (16). The value of $P$ in each case is stated, and cannot be regarded as significant if greater than 0.05 .

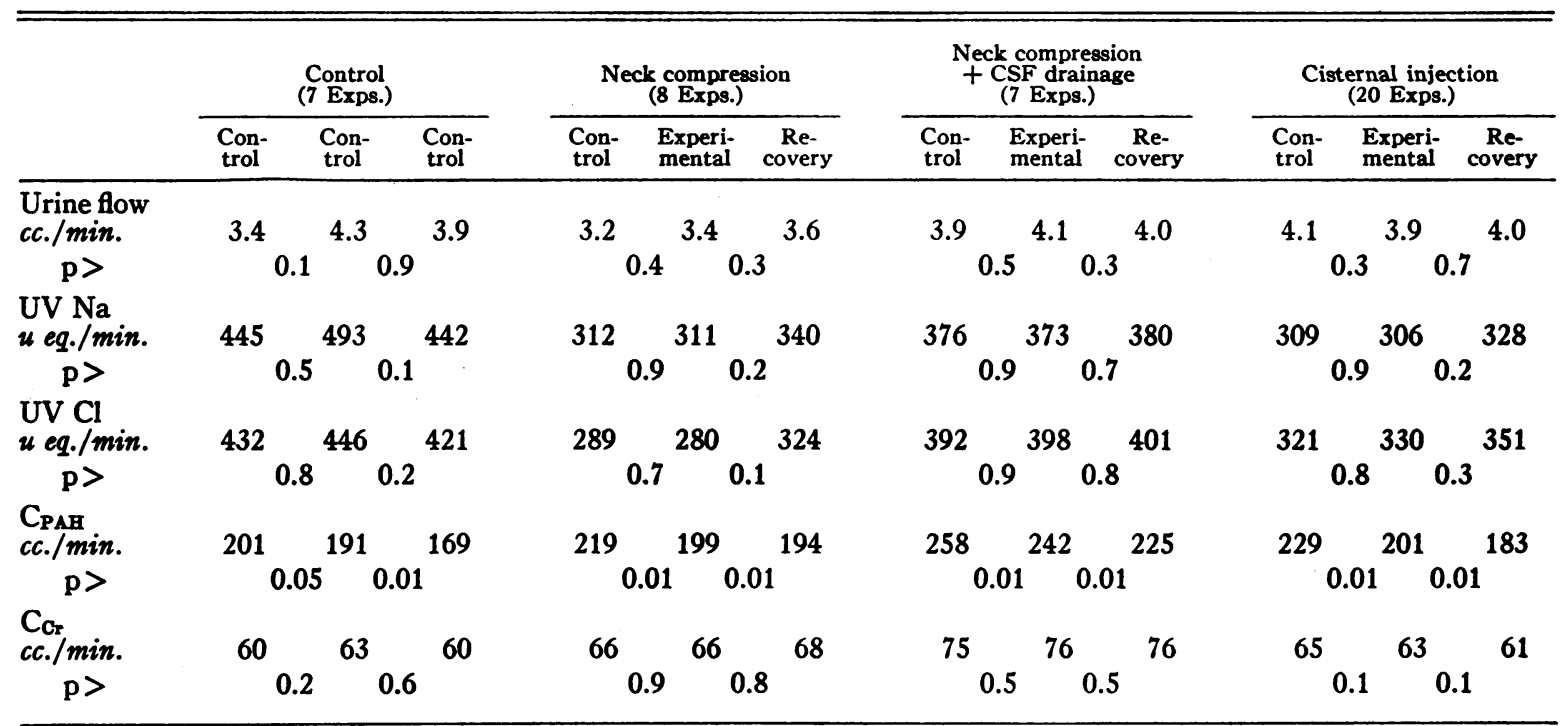

water. Neither venous pressure in the jugular bulb nor arterial pressure was altered.

Urinary flow, the excretion of sodium and chloride, and the clearances of creatinine and PAH were not significantly altered, when compared with the control studies, by any of the experimental procedures described above. The data are detailed in Table I. It should be noted that the $\mathrm{C}_{\mathrm{PAB}}$ gradually fell during the entire period of infusion in all experiments. This change may be attributed to the influence of pentobarbital anesthesia (17).

In view of the known effects of pentobarbital anesthesia on renal function (17), two additional experiments were done using chloralose anesthesia. In these, cisternal injection of saline was also without effect on the excretion of salt.

To ascertain whether the saline load in these experiments might interfere with the urinary response to the experimental procedure, three experiments were performed on dogs who received no intravenous infusion. In two dogs, the excretion of sodium and chloride, during a one hour period during which the CSF pressure was maintained at $500 \mathrm{~mm}$. water by cisternal injection of saline, did not differ significantly from the salt excretion during the one hour control period or the one hour recovery period. In one dog similarly studied, but subjected to a one hour period of neck compression and CSF drainage, the excretion of sodium and chloride was not altered. Thus the pattern of salt excretion was not influenced by these procedures in the presence or absence of a saline load.

\section{DISCUSSION}

Acute alterations in the volume of plasma or extracellular fluid have been reported to induce alterations in the urinary excretion of sodium and chloride $(18,19)$. However, there is no evidence that the disturbances in electrolyte excretion associated with lesions of the central nervous system are related to alterations in the intracranial volume of blood or extracellular fluid. Harrison and coworkers have reported that compression of the neck of the sitting man results in an increased urinary excretion of sodium and chloride $(9,10)$. This procedure had little or no effect in recumbent subjects. One explanation for this difference might relate to differences in the volume of the intracranial veins rather than to the pressure of this system. Since, in the sitting position, the intracranial CSF pressure is lower than it is in the recumbent posture, jugular compression in the sitting position might be expected to produce greater distention of intracranial veins than if the 
subject were supine. There are no methods for directly measuring the volume of CSF or the intracranial venous volume. However, these two volumes vary inversely if the total volume of the cranial cavity is kept essentially constant (20). Thus cerebrospinal fluid drainage was used in the experiments of Group 3 to induce distention of the intracranial veins. The absence of any change in salt excretion despite compression of the neck (Group 2) and reduction of the CSF pressure to minus $150 \mathrm{~mm}$. water (Group 3), suggests that an acute increase in intracranial venous volume is without effect on renal function. In the experiments of Group 4, a primary increase in the pressure and the volume of the CSF was produced, presumably associated with a decrease in the intracranial venous volume (20). Under these circumstances no alteration in renal function was noted. In four of the twenty experiments performed, the excretion of sodium and chloride fell to 30 to 50 per cent of the control value when the CSF pressure was elevated, and immediately returned to the control rate of excretion when the pressure was reduced. This change was not statistically significant $(p>0.8)$.

When the CSF pressure is elevated to the level of the arterial diastolic pressure, there follows a secondary rise in arterial pressure (21). This is associated with an acute reduction in urinary flow, a manifestation of extreme renal vasoconstriction secondary to presumed anoxic stimulation of the vasomotor center (22). In the present experiments, however, the CSF pressure was elevated to a level well below diastolic arterial blood pressure and alterations in systemic blood pressure or renal plasma flow did not occur.

Thus, neither an increase nor a decrease in intracranial venous distention or cerebrospinal fluid pressure and volume could be demonstrated to affect renal hemodynamics, urinary flow, or excretion of sodium and chloride. It is also of interest that an acute reduction of cerebral blood flow, produced by ligation of the carotid arteries bilaterally in the dog, is similarly without effect on the excretion of sodium and chloride (23).

These experiments fail to support the hypothesis that there is an intracranial "volume receptor" influencing the renal excretion of sodium and chloride in the anesthetized dog.

\section{SUMMARY}

Alterations in intracranial venous pressure and venous volume, and the pressure and volume of cerebrospinal fluid, have been studied for their effect on renal function in the anesthetized dog. The excretion of sodium and chloride, urinary flow, and clearances of creatinine and paraminohippurate are not significantly influenced by altering pressure-volume relationships of the cerebral venous system and the cerebrospinal fluid.

\section{ACKNOWLEDGMENTS}

The valuable suggestions of Dr. Franklin $H$. Epstein in planning these experiments, and the continued encouragement of Dr. Robert Galambos and Dr. David McK. Rioch are gratefully appreciated.

\section{REFERENCES}

1. Jungmann, P., and Meyer, E., Experimentelle Untersuchungen über die Abhängigkeit der Nierenfunktion vom Nervensystem. Arch. f. exper. Path. $u$. Pharmakol., 1913, 73, 49; Jungmann, P., Uber die Beziehungen des zuckerstiches zum sogen. Salzstich. Ibid., 1914, 77, 122.

2. Peters, J. P., Welt, L. G., Sims, E. A. H., Orloff, J., and Needham, J., A salt-wasting syndrome associated with cerebral disease. Tr. A. Am. Physicians, 1950, 63, 57.

3. Welt, L. G., Seldin, D. W., Nelson, W. P., German, W. J., and Peters, J. P., Role of the central nervous system in metabolism of electrolytes and water. Arch. Int. Med., 1952, 90, 355.

4. Lewy, F. H., and Gassmann, F. K., Experiments on the hypothalamic nuclei in the regulation of chloride and sugar metabolism. Am. J. Physiol., 1935, 112, 504.

5. Allott, E. N., Sodium and chlorine retention without renal disease. Lancet, 1939, 1, 1035.

6. Sweet, W. H., Cotzias, G. C., Seed, J., and Yakovlev, P. I., Gastro-intestinal hemorrhages, hyperglycemia, azotemia, hyperchloremia and hypernatremia following lesions of the frontal lobe in man. A. Research Nerv. \& Ment. Dis., Proc., The Frontal Lobes, 1938, 27, 795.

7. Higgins, G., Lewin, W., O'Brien, J. R. P., and Taylor, W. H., Metabolic disorders in head injury. Hyperchloraemia and hypochloruria. Lancet, 1951, 1, 1295.

8. Cooper, I. S., and Crevier, P. H., Neurogenic hypernatremia and hyperchloremia. J. Clin. Endocrinol. \& Metab., 1952, 12, 821.

9. Lewis, J. M., Jr., Buie, R. M., Sevier, S. M., and Harrison, T. R., The effect of posture and of congestion of the head on sodium excretion in normal subjects. Circulation, 1950, 2, 822. 
10. Viar, W. N., Oliver, B. B., Eisenberg, S., Lombardo, T. A., Willis, K., and Harrison, T. R., The effect of posture and of compression of the neck on excretion of electrolytes and glomerular filtration: Further studies. Circulation 1951, 3, 105.

11. Strauss, M. B., Davis, R. K., Rosenbaum, J. D., and Rossmeisl, E. C., "Water diuresis" produced during recumbency by the intravenous infusion of isotonic saline solution. J. Clin. Invest., 1951, 30, 862.

12. Strauss, M. B., Davis, R. K., Rosenbaum, J. D., and Rossmeisl, E. C., Production of increased renal sodium excretion by the hypotonic expansion of extracellular fluid volume in recumbent subjects. J. Clin. Invest., 1952, 31, 80.

13. Bonsnes, R. W., and Taussky, H. H., On the colorimetric determination of creatinine by the Jaffe reaction. J. Biol. Chem., 1945, 158, 581.

14. Smith, H. W., Finkelstein, N., Aliminosa, L., Crawford, B., and Graber, M., The renal clearances of substituted hippuric acid derivatives and other aromatic acids in dog and man. J. Clin. Invest., 1945, 24, 388.

15. Schales, O., and Schales, S. S., A simple and ac- curate method for the determination of chloride in biological fluids. J. Biol. Chem., 1941, 140, 879.

16. Fisher, R. A., Statistical Methods for Research Workers. Oliver and Boyd, 1938, p. 125.

17. Glauser, K. F., and Selkurt, E. S., Effect of barbiturates on renal function in the dog. Am. J. Physiol., 1952, 168, 469.

18. Peters, J. P., Sodium, water and edema. J. Mt. Sinai Hosp., 1950-51, 17, 159.

19. Wolf, A. V., The Urinary Function of the Kidney. Grune and Stratton, New York, 1950.

20. Ryder, H. W., Espey, F. F., Kimbell, F. D., Penka, E. J., Rosenauer, A., Podolsky, B., and Evans, J. $P$. ., The mechanism of the change in cerebrospinal fluid pressure following an induced change in the volume of the fluid space. J. Lab. \& Clin. Med., 1953, 41, 428.

21. Cushing, $H$., Concerning a definite regulatory mechanism of the vaso-motor centre which controls blood pressure during cerebral compression. Bull. Johns Hopkins Hosp., 1901, 12, 290.

22. Salk, M. R., and Weinstein, R. E., On the effects of acutely raised intracranial pressure on diuresis in the dog. Am. J. Physiol., 1939, 126, 316.

23. Unpublished data. 